\title{
Parameter identification as the basis for finite element simulations of ultimate limit states of concrete hinges
}

\author{
J. Kalliauer \& T. Schlappal \\ Institute for Mechanics of Materials and Structures, TU Wien —Vienna University of Technology, Vienna, Austria
}

H.A. Mang

Institute for Mechanics of Materials and Structures, TU Wien-Vienna University of Technology, Vienna, Austria College of Civil Engineering, Tongji University, Shanghai, China

B. Pichler

Institute for Mechanics of Materials and Structures, TU Wien-Vienna University of Technology, Vienna, Austria

\begin{abstract}
Reinforced concrete hinges, subjected to eccentric compression, are failing in a ductile fashion (Schlappal et al. 2017). Three-dimensional Finite Element simulations are prime candidates for a more detailed analysis of this interesting structural behavior. Such nonlinear simulations, however, typically require pocedures for updating of the underlying models. They involve fitting of input parameters such that the output of the simulations agree with experimental measurements (Kalliauer et al. 2017). In the present contribution, it is investigated to which extent fitting procedures, involving time-consuming nonlinear three-dimensional Finite Element simulations, can be avoided. Therefore, input parameters are identified by combining (i) results from destructive and nondestructive compression tests on plain concrete specimens, (ii) results from centric and eccentric compression tests on concrete hinges subjected to serviceability loads, (iii) a multiscale model for tensile failure of concrete, and (iv) linear-elastic twodimensional Finite Element simulations. Parameter identification aims of (i) quantifying the influence of damage of concrete (resulting from restrained shrinkage prior to structural testing) on the elastic stiffness, the tensile strength, and the fracture energy, and of (ii) determination of the characteristic triaxiality of the compressive stress states, prevailing in the neck region, in order to ensure modeling of the triaxial compressive strength of concrete in accordance with regulations of Eurocode 2. After parameter identification, a nonlinear three-dimensional Finite Element simulation of the bearing capacity tests by Schlappal et al. (2017) is carried out. The obtained numerical results agree well with experimental observations. This underlines the usefulness of the presented parameter identification strategy.
\end{abstract}

\section{INTRODUCTION}

Concrete hinges were invented by Freyssinet in the first half of the 20th century (Freyssinet 1923, Freyssinet 1954). They represent necks of monolithically produced reinforced concrete structures (Marx \& Schacht 2010a, Schacht \& Marx 2010). In order to allow these necks to act as structural hinges, their bending stiffness must be significantly smaller than that of the connected reinforced concrete parts. Therefore, only a few pairs of inclined steel bars run across the center of the neck, which is their crossover point. In addition, as part of the concept, concrete hinges may exhibit bending-induced tensile cracking under regular service loads (Leonhardt \& Reimann 1965, Leonhardt 1986, Marx \& Schacht 2010a, Marx \& Schacht 2010b, Marx \& Schacht 2010c). Concrete hinges are used as supports in integral bridge construction (Sallenbach 1967, Marx \& Schacht 2010a, Schacht \& Marx
2010, Schacht \& Marx 2015, Morgenthal \& Olney 2016) and as segment-to-segment interfaces of segmented linings in mechanized tunnelling (Janßen 1983, Hordijk et al. 1996, De Waal 2000, Blom 2002, Maidl et al. 2012, Jusoh et al. 2015).

Pioneering design guidelines for concrete hinges were developed in the 1960s by Leonhardt and Reimann (1965). More recently, they were improved in order to be applicable within the presently used semi-probabilistic safety concept (Marx \& Schacht 2010a, Marx \& Schacht 2010b, Marx \& Schacht 2010c, Schacht \& Marx 2010). Still, it is noteworthy that the original guidelines refer to ServiceabilityLimit-States rather than to Ultimate-Limit-States. This was the motivation to carry out experiments (Schlappaletal.2017)and to re-analyze them by means of Finite Element simulations (Kalliauer et al. 2017). These simulations were based on default input parameters. The latter were derived from the uniaxial compressive strength and from Young's modulus, 
measured on plane concrete specimens 28 days after their production. Corresponding simulation results overestimated the load bearing capacity of concrete hinges by $80 \%$. This resulted in the need for a model updating procedure, involving the fitting of input parameters such that the output from simulations agreed with experimental measurements. The number of fitting parameters could be reduced significantly by involving a recently developed multiscale model for tensile failure of plain concrete (Hlobil et al. 2017).

The aim of the present contribution is to check to which extent a thorough analysis of experiments, carried out on plane concrete prisms and on reinforced concrete hinges, allows for identification of material properties of concrete that yield satisfactory Finite Element simulation results without the need of a fitting procedure on the level of nonlinear three-dimensional structural analyses. To this end, the contribution is structured as follows. Section 2 contains a collection of experimental data on plain concrete prisms and on concrete hinges subjected to centric and eccentric compression. In Section 3, a thorough analysis of the experimental data is carried out in order to quantify input parameters for subsequent Finite Element simulations. Section 4 is devoted to the Finite Element simulation of the bearing capacity of concrete hinges subjected to eccentric compression. Conclusions drawn from this study are presented in Section 5.

\section{EXPERIMENTAL DATA}

Schlappal et al. (2017) carried out compression experiments on plain concrete specimens and reinforced concrete hinges.

\subsection{Properties of reinforced concrete hinges}

The shape of the tested concrete hinges and the arrangement of the steel reinforcement (Fig. 1) were designed in accordance with guidelines by

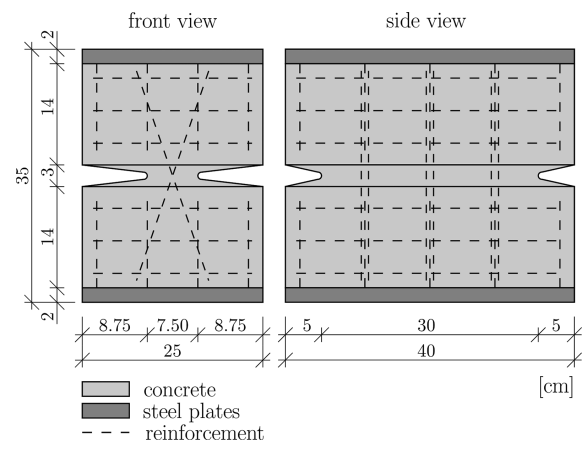

Figure 1. Formwork drawing of the analyzed concrete hinges; after (Schlappal et al. 2017).
Leonhardt and Reimann (1965). The reinforcement ratio amounted to

$\rho=\frac{A_{s}}{A}=1.3 \%$,

where $A_{s}$ and $A=7.5 \mathrm{~cm} \times 30 \mathrm{~cm}=225 \mathrm{~cm}^{2}$, respectively, denote the cross-sectional area, occupied by steel and the reinforced neck (Fig. 1). Young's modulus of the structural steel amounted to (British Standards Institution and CEN European Committee for Standardization 2015b)

$E_{s}=210 \mathrm{GPa}$.

To avoid that the concrete hinges, subjected to compressive line loads, will crush locally in the immediate vicinity of the load application system, steel plates were welded onto the top and bottom reinforcement cages before casting (Fig. 1). Three nominally identical concrete hinges were tested, one after the other.

In order to quantify structural creep of concrete hinges, they were subjected, for four hours each, to centric compression, amounting to $200 \mathrm{kN}$. The changes of the opening of the lateral notches were measured by six inductive displacement sensors (Schlappal et al. 2017). Test results have indicated that the experiments could be reproduced satisfactory, see the thick solid lines in Fig. 2 for the creep strain evolution under sustained loading, normalized with respect to the creep strain reached at the end of the loading process.

In order to quantify bending-induced tensile cracking, each of the three concrete hinges were subjected to three consecutive eccentric compression tests, using line loads, incrementally increased by $25 \mathrm{kN}$ up to $200 \mathrm{kN}$. The three tests for each specimen referred to three different load eccentricities:

$e=\{20 \mathrm{~mm}, 22 \mathrm{~mm}, 24 \mathrm{~mm}\}$.

After each load increment, the tests were interrupted for 10 seconds, in order to take images of the

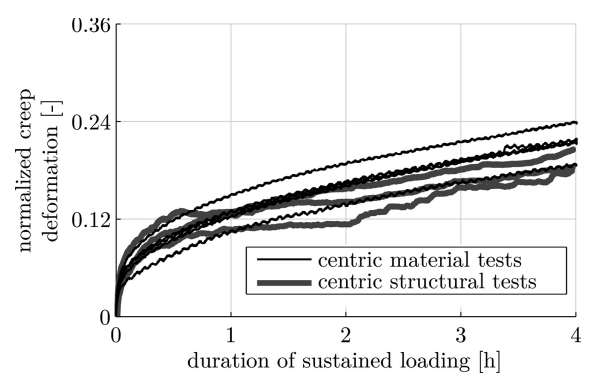

Figure 2. Evolution of creep deformations under sustained loading, normalized by the averaged deformation at the end of the loading process; after (Schlappal et al. 2017). 


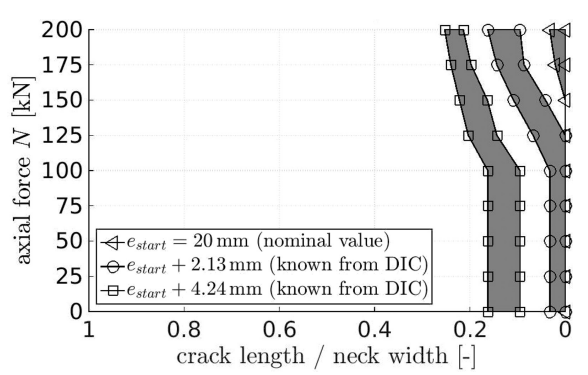

Figure 3. Bending-induced cracking of concrete hinges under eccentric compression: crack length as a function of eccentricity and load level; after (Schlappal et al. 2017).

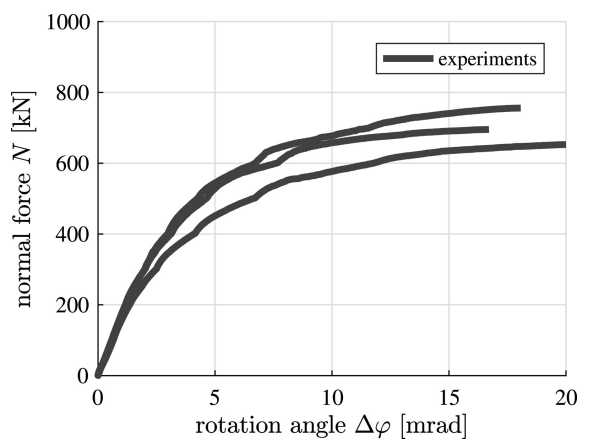

Figure 4. Rotation angles across the neck regions of three concrete hinges, as a function of eccentric loading ( $e=25 \mathrm{~mm})$ up to the load-carrying capacity; after (Schlappal et al. 2017).

front-side and the back-side notches, using cameras of a Digital Image Correlation system. This way, the crack length could be determined as a function of the eccentricity and the load level, see Fig. 3.

In order to quantify the bearing capacity of the concrete hinges, they were subjected to eccentric compression with an eccentricity of $e=25 \mathrm{~mm}$. Ultimate load levels amounted to $654 \mathrm{kN}, 695 \mathrm{kN}$ and 756 kN, see Fig. 4.

\subsection{Properties of plain concrete specimens}

The cube compressive strength, $f_{\text {c.cube }}$, and the Young's modulus, $E_{c}$, were determined 28 days after production, following the Austrian standards for testing of concrete (Austrian Standards Institute 2010):

$$
f_{c, \text { cube }}=56.25 \mathrm{MPa}, \quad E_{c}=34.75 \mathrm{GPa} .
$$

As for characterization of creep, concrete prisms were subjected, for four hours each, to centric compression, equal to nearly $20 \%$ of the short-term uniaxial compressive strength. Five tests on nominally identical specimens were carried out. Three tests delivered nearly the same creep response, bounded by the results from the other two tests. The thin solid lines in Fig. 2 refer to the evolution of the creep strains under sustained loading, normalized with respect to the creep strain reached end the end of the loading process.

\section{INPUT PARAMETERS FOR STRUCTURAL SIMULATIONS}

Reinforced concrete hinges are prone to develop shrinkage-induced damage in the neck region (Leonhardt and Reimann 1965), reducing the elastic stiffness, the tensile strength, and the fracture energy of concrete. In addition, concrete hinges are known to exhibit triaxial compressive stress states in the neck region. This calls for realistic modeling of the triaxial compressive strength of concrete.

As for material modeling of concrete, the "CC3DNonLinCementitious" model (Červenka and Papanikolaou 2008) of the Finite Element software "Atena Science" (Červenka Consulting et al. 2016) was used. It is based on a MenétreyWillam failure surface (Menétrey and Willam 1995). Corresponding input values for Finite Element simulations of the bearing capacity tests (Fig. 4) requires identification of input values for the mentioned concrete model.

\subsection{Identification of the elastic stiffness of damaged concrete}

On average the plain concrete prisms exhibited a creep activity which was by $12.7 \%$ larger than that of the reinforce concrete hinges (Fig. 2). This experimental observation will be used for identification of the damaged elastic stiffness of concrete in the neck region of the concrete hinges. It is based on considerations regarding stress-concentration, see Ross (1958) for a similar approach.

Consider that (i) the plain concrete prisms were subjected to a compressive stress $\sigma$, and that (ii) the reinforced neck region is subjected to the same average stress, such that the compressive force $F$ amounts to $\sigma \cdot A$, where $A$ denotes to total crosssection of the neck of the concrete hinges. Decomposing $A$ into the areas occupied by concrete, $A_{c}$, and the one by steel, $A_{s}$, delivers

$$
A=A_{c}+A_{s} \text {. }
$$

Introducing the average stress within the concrete, $\sigma_{c}$, and the steel, $\sigma_{s}$, respectively, and formulating force equilibrium in loading direction yields

$$
\sigma A=\sigma_{c} A_{c}+\sigma_{s} A_{s} .
$$

In order to establish a relation between $\sigma_{c}$ and $\sigma_{s}$, firm bond between concrete and steel is assumed. 
This results in the following strain compatibility condition

$\varepsilon_{\mathrm{c}}=\varepsilon_{\mathrm{s}}$.

Considering elastic deformations, the strains in Eq. (7) are linked to the stresses in Eq. (6) by means of Hooke's law, such that Eq. (7) can be rewritten as

$$
\frac{\sigma_{c}}{E_{c d}}=\frac{\sigma_{s}}{E_{s}}
$$

where $E_{c d}$ denotes the damaged stiffness of concrete in the neck region. Solving Eq. (8) for $\sigma_{s}$, inserting the resulting expression into Eq. (6), and solving the obtained expression for the stress ratio $\sigma / \sigma_{c}$ delivers

$$
\frac{\sigma}{\sigma_{c}}=\frac{A_{c}}{A}+\frac{E_{s}}{E_{c d}} \frac{A_{s}}{A} .
$$

Using Eqs. (1) and (5), Eq. (9) can be reformulated as follows:

$$
\frac{\sigma}{\sigma_{c}}=(1-\rho)+\frac{E_{s}}{E_{c d}} \rho
$$

Eq. (10) underlines that the average stress in the neck region is by a factor of $\sigma / \sigma_{c}$ larger than the average stress within the creeping concrete.

The experimental results of Fig. 2 are interpreted as follows: creeping of the reinforced concrete neck was smaller than in the plane concrete prisms, because the average stress level of the creeping concrete is by a factor of $\sigma / \sigma_{c}$ smaller than the average stress of the reinforced neck region. This is the motivation to set $\sigma / \sigma_{c}$ in Eq. (10) equal to the experimentally observed normalized creep strain ratio, amounting to 1.127, see Fig. 2. Solving the resulting expression for the stiffness of damaged concrete and specializing the results for Eqs. (1) and (2), delivers

$E_{c d}=\frac{E_{s} \rho}{1.127-(1-\rho)}=19.5 \mathrm{GPa}$.

\subsection{Identification of the crack density parameter}

The elastic stiffness of undamaged concrete, see Eq. (4), and of damaged concrete, see Eq. (11) allows for estimation of Budiansky and O'Connel's crack density parameter $\omega$. To this end, concrete is considered to be damaged by parallel open cracks. Young's modulus in the direction normal to the crack plane is estimated, using a multiscale model for damaged concrete, see (Pichler et al. 2007, Hlobil et al. 2017), as
$E_{c d}=E_{c}\left[1+\frac{16 \omega}{3}\left(1-v_{c}^{2}\right)\right]^{-1}$.

Solving Eq. (12) for the damage variable $\omega$ and consideration of Eqs. (4) and (11) as well as the standard value of Poisson's ratio of concrete, $v_{c}=0.20$, see British Standards Institution and CEN European Committee for Standardization (2015a), delivers

$\omega=\left(\frac{E_{c}}{E_{c d}}-1\right) \frac{3}{16\left(1-v_{c}^{2}\right)}=15.3 \%$.

\subsection{Identification of the damaged uniaxial tensile strength of concrete}

Bounds of the damaged tensile strength of concrete can be determined, based on the experimental observation that tensile cracking of the concrete hinges starts between the compressive load levels

$N \in[150 \mathrm{KN} ; 175 \mathrm{KN}]$,

acting with an eccentricity of $e=20 \mathrm{~mm}$, see Fig. 3. The maximum tensile stress, $\max \sigma_{t}$, resulting from the combined action of a normal force $N$ and a bending moment $M=N e$, was quantified by Schlappal et al. (2017), by means of results from linear-elastic plane-strain Finite Element analyses of the investigated concrete hinges:

$\max \sigma_{t}=2.77 \frac{N}{a b}-2.00 \frac{6(\mathrm{Ne})}{a^{2} b}$,

where $a b$ denotes the cross-sectional area of the neck and $a^{2} b / 6$ stands for beam theory-related elastic section modulus. Furthermore, 2.77 and 2.00 are numerically determined stress increase factors relative to the stress levels according to beam theory. Specializing Eq. (15) for $e=20 \mathrm{~mm}, a=75 \mathrm{~mm}$, $b=300 \mathrm{~mm}$, and for the two bounds of the normal force given in (14), delivers experimentally-derived bounds of the damaged tensile strength of concrete, amounting to

$f_{t, d a m} \in[2.87 \mathrm{MPa} ; 3.34 \mathrm{MPa}]$.

A more precise estimate of the damaged tensile strength is determined by means of a multiscale analysis of tensile failure of concrete by Hlobil et al. (2017). This model is based on the following relation between the tensile strength of the undamaged and damaged material:

$f_{t, \text { dam }}=\frac{f_{t}}{\sqrt{1+1.223 \omega}}$. 
The tensile strength of undamaged concrete, $f_{t}$, is estimated by the following standard relation (fib 2013)

$$
f_{t}=0.3 \mathrm{MPa} \cdot\left(\frac{0.85\left(f_{c, \text { cube }}-8 \mathrm{MPa}\right)}{1 \mathrm{MPa}}\right)^{2 / 3}
$$

Specializing Eq. (18) for the value of $f_{c, \text { cube }}$ from Eq. (4), delivers

$f_{t}=3.57 \mathrm{MPa}$.

Specializing Eq. (17) for Eqs. (13) and Eq. (19) yields

$$
f_{t, d a m}=3.28 \mathrm{MPa} \text {. }
$$

Notably, Eq. (20) satisfies the corresponding bounds, see Eq. (16).

\subsection{Identification of the fracture energy of damaged concrete}

Atena science (Červenka et al. 2016) suggest the following value of the fracture energy for concrete with a cube compressive strength according to Eq. (4):

$G_{f}=147 \mathrm{~J} / \mathrm{m}^{2}$.

Shrinkage-induced cracking reduces this value by an increment $\Delta G_{f}$. The latter is quantified on the basis of a smeared crack model as

$\Delta G_{f}=\int_{0}^{\mathrm{w}_{d}} \sigma \mathrm{dw}$,

where $\sigma$ and w denote the cohesive stress and the smeared crack opening displacement, respectively. The relation between these two quantities is given by Hordijk (1991) as

$$
\begin{aligned}
\sigma=f_{t} & \cdot\left\{\left[1+\left(c_{1} \frac{\mathrm{w}}{\mathrm{w}_{\mathrm{c}}}\right)^{3}\right] \exp \left(-c_{2} \frac{\mathrm{w}}{\mathrm{w}_{\mathrm{c}}}\right)\right. \\
& \left.-\frac{\mathrm{w}}{\mathrm{w}_{\mathrm{c}}}\left(1+c_{1}^{3}\right) \exp \left(-c_{2}\right)\right\},
\end{aligned}
$$

with (Červenka et al. 2016)

$c_{1}=3, \quad c_{2}=6.93, \quad \mathrm{w}_{c}=5.14 G_{f} / f_{t}$.

The smeared crack opening displacement $w_{d}$, related to shrinkage-induced damage, is determined by specializing Eq. (23) for Eqs. (24), $\sigma=f_{\text {t,dam }}$, and $\mathrm{W}=\mathrm{w}_{d}$, and inserting Eqs. (19)-(21) into the resulting expression, followed by solving the latter for $w_{d}$ as:

$\mathrm{w}_{d}=2.6 \mu \mathrm{m}$
Inserting of the functions of Eqs. (23)-(25) into Eq. (22) and consideration of Eqs. (19)-(21) yields

$\Delta G_{f}=8.893 \mathrm{~J} / \mathrm{m}^{2}$.

Subtracting $\Delta G_{f}$ from $G_{f}$, see Eqs. (21) and (26), yields the value of the effective fracture energy of the damaged concrete as

$G_{f d}=G_{f}-\Delta G_{f}=138.1 \mathrm{~J} / \mathrm{m}^{2}$.

\subsection{Identification of the stress triaxiality in the neck region}

Concrete hinges exhibit triaxial compressive stress states in the neck region (Leonhardt \& Reimann 1965). In order to quantify a characteristic principal stress ratio, a linear-elastic plane-strain Finite Element simulation is carried out with an load eccentricity $e$ amounting to $25 \mathrm{~mm}$. The principal stress ratios are evaluated in the smallest crosssection of the neck. Averaging them in the region between the surface of the root of the compressed notch and a distance from that surface, amounting to the maximum aggregate size of $16 \mathrm{~mm}$, delivers the average principal stress ratio as

$\sigma_{1}: \sigma_{2}: \sigma_{3}=1.00: 0.45: 0.30$.

The stress ratios in Eq. (28) allow for calculating corresponding Haigh-Westergaard coordinates as (Menétrey \& Willam 1995, Grassl \& Jirásek 2006)

$\xi=1.01 \sigma_{1}, \quad \rho=0.521\left|\sigma_{1}\right|, \quad \vartheta=0.842 \mathrm{rad}$,

where $\sigma_{1}$ denotes the compressive principal normal stress in loading direction and $\xi, \rho$, and $\vartheta$ stand for the hydrostatic and deviatoric component of the characteristic stress state and for its Lode angle, respectively.

\subsection{Eurocode-based description of the triaxial strength of concrete}

The triaxial-to-uniaxial strength ratio of concrete, $F$, is estimated on the basis of recommendations for partially loaded areas according to Eurocode 2-1-1 (British Standards Institution and CEN European Committee for Standardization 2015a), see also (Marx and Schacht 2010a, Marx and Schacht 2010b, Marx and Schacht 2010c, Kalliauer et al. 2017). The strength ratio $F$ depends on geometric dimensions and reads as:

$F=\sqrt{A_{c 1} / A_{c 0}}$,

where $A_{c 1}$ is equal to the thickness of the concrete hinge $(40 \mathrm{~cm})$ times three times the neck width, $3_{b 1}$, 
see (British Standards Institution and CEN European Committee for Standardization 2015a), and $A_{c 0}$ denotes the loaded neck-area that is equal to the thickness of the neck $(30 \mathrm{~cm})$ times the neck width $b_{1}$, see Fig. 5. Therefore, the triaxial-to-uniaxial compressive strength ratio of concrete amounts to

$F=\sqrt{\frac{40 \mathrm{~cm} \cdot 3 b_{1}}{30 \mathrm{~cm} \cdot b_{1}}}=2$.

\subsection{Identification of the slope of the Menétrey-Willam failure surface in the Haigh-Westergaard stress space}

The Menétrey-Willam failure surface is defined as (Menétrey and Willam 1995, Červenka and Papanikolaou 2008, Červenka and Červenka 2013)

$$
F_{s P}^{p}(\xi, \rho, \vartheta)=\frac{3}{2}\left(\frac{\rho}{f_{c}^{\prime}}\right)^{2}+\frac{m}{f_{c}^{\prime}}\left(\rho \frac{r(\vartheta)}{\sqrt{6}}+\frac{\xi}{\sqrt{3}}\right)-c=0,
$$

where $m$ and $r(\vartheta)$, respectively, are defined as

$$
m=\frac{3 e_{\sigma}}{e_{\sigma}+1} \frac{f_{r}^{\prime 2}-f_{t}^{\prime 2}}{f_{r}^{\prime} f_{t}^{\prime}},
$$

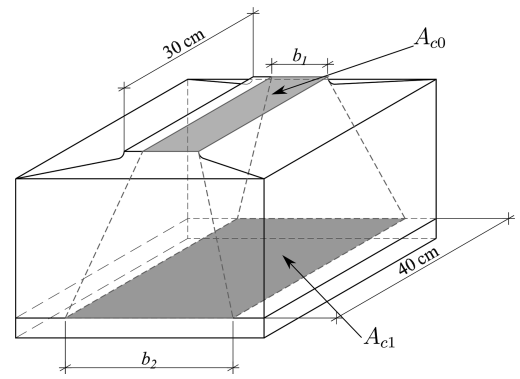

Figure 5. Application of regulations of Eurocode 2 regarding partially loaded areas to concrete hinges; after (Kalliauer et al. 2017).

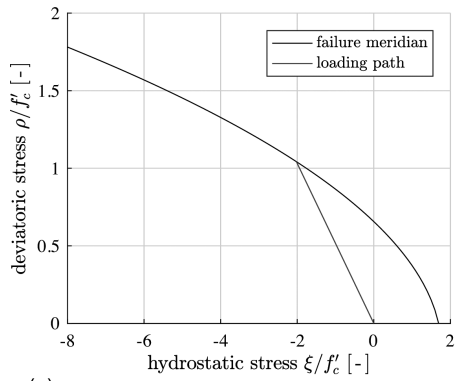

(a) and

$r(\vartheta)=\frac{4\left(1-e_{\sigma}^{2}\right) \cos ^{2} \vartheta+\left(2 e_{\sigma}-1\right)^{2}}{2\left(1-e_{\sigma}^{2}\right) \cos \vartheta+\left(2 e_{\sigma}-1\right) H}$

with

$$
H=\sqrt{4\left(1-e_{\sigma}^{2}\right) \cos ^{2} \vartheta+5 e_{\sigma}^{2}-4 e_{\sigma}} .
$$

see also Fig. 6.

The initial value of the hardening/softening parameter $\mathrm{c}$ is given as $c_{i n i}=1$ (Červenka et al. 2016). The "eccentricity" $e_{\sigma}=0.52$ controls the shape of the failure surface in the deviatoric planes. The elastic limit stress under uniaxial compression, $f_{c}^{\prime}$, increases - during strain hardening - from its initial value, $f_{c 0}$, up to the uniaxial compressive strength, $f_{c}$. The uniaxial tensile strength of the MenétreyWillam failure surface, $f_{t}^{\prime}$, is an auxiliary value, because it is larger than the actual uniaxial tensile strength, $f_{t}$. The latter is modeled by a Rankine criterion. The ratio of the auxiliary-toreal uniaxial tensile strength

$$
\lambda_{t}=\frac{f_{t}^{\prime}}{f_{t}^{\prime}}
$$

is another input parameter for Finite Element simulations with Atena science. In order to obtain a triaxial-to-uniaxial strength ratio $F=2$, see Eqs. (31), for the characteristic triaxial compressive stress state defined in Eq. (28), the numerical value of $\lambda_{t}$ must amount to

$\lambda_{t}=8.9$,

see also Fig. 6.

\section{STRUCTURAL SIMULATIONS BY MEANS OF THE FINITE ELEMENT METHOD}

The bearing capacity tests described in Section 2 are simulated by Atena science, the material model

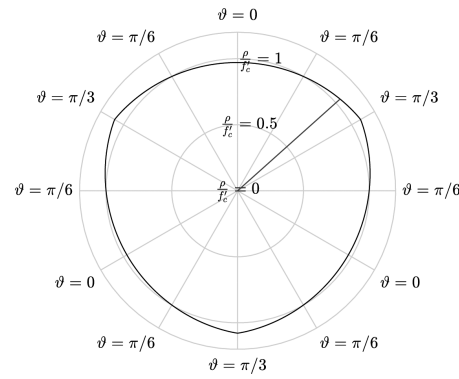

(b)

Figure 6. Representation of the Menétrey-Willam failure surface in the Haigh-Westergaard stress space (a) section containing the hydrostatic axis (see abscissa), and (b) deviatoric plane; the blue graph represents (the projection of ) the stress path resulting from proportional increase of a triaxial compressive stress state with principal stress ratios given in Eq. (28). 


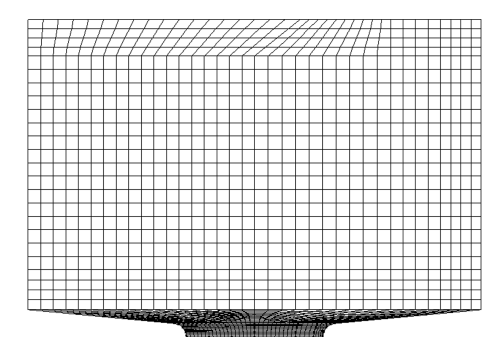

(a)

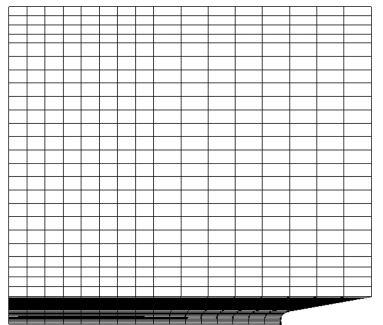

(b)

Figure 7. Three-dimensional Finite Element mesh consisting of 27776 hexahedral elements with a characteristic element size of $1.25 \mathrm{~mm}$ in the neck region: (a) front view, (b) lateral view; exploiting double symmetry of the problem, only one fourth of the reinforced concrete hinge is discretized.

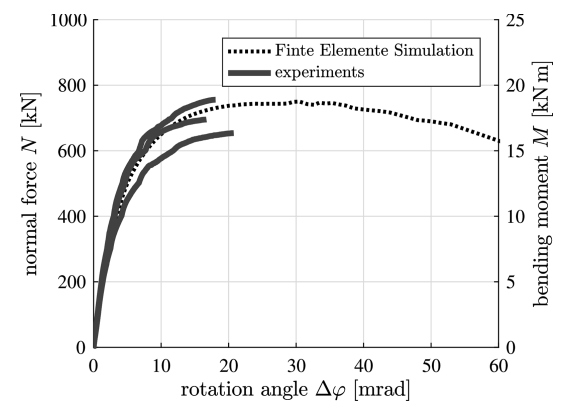

Figure 8. Behavior of concrete hinges subjected to eccentric compression $(e=25 \mathrm{~mm})$ up to their bearing capacity: comparison of experimental observations (see the blue graphs) with results from nonlinear three-dimensional Finite Element simulations using Atena science, the material model "CC3DNonLinCementitious", and the input parameters derived above.

"CC3DNonLinCementitious", and the previously derived input parameters. Default values are used for those input values that have not been discussed above.

The Finite Element mesh shown in Fig. 7, consists of 27776 hexahedral elements with trilinear displacement interpolation, 31730 nodes, and 95190 degrees of freedom. This mesh was the result of a convergence study, documented in (Kalliauer 2016).

The numerical simulations reproduce the experimentally observed behavior both qualitatively and quantitatively in a satisfactory fashion, and they provide insight into the post-peak softening behavior of the concrete hinges, which was not quantified experimentally, see Fig. 8.

\section{DISCUSSION AND CONCLUSIONS}

The bearing capacity of reinforced concrete hinges, subjected to eccentric compression, was investigated by means of experiments and threedimensional Finite Element simulations. The required input parameters for nonlinear numerical simulations were identified a priori, by combining (i) results from destructive and nondestructive compression tests on plain concrete specimens, (ii) results from centric and eccentric compression tests on concrete hinges subjected to serviceability loads, (iii) a multiscale model for tensile failure of concrete, and (iv) linear-elastic plane-strain Finite Element simulations. In other words, identification of input parameters was carried out without fitting the results from nonlinear structural simulations to the experimentally observed behavior. Therefore, the described nonlinear three-dimensional numerical simulation represents a nontrivial quantitative test of the predictive capabilities of the developed Finite Element model. This test was passed successfully. Hence, the developed Finite Element model is validated. This is useful for the future development of nonlinear interface laws that are necessary prerequisites for the analysis of Ultimate Limit States of integral bridges and of segmented tunnel rings.

\section{FUNDING AND ACKNOWLEDGMENTS}

Financial support by the Austrian Science Fund (FWF) provided within the project P 281 31-N32 "Bridging the Gap by Means of Multiscale Structural Analysis" and corresponding discussions with Yong Yuan (Tongji University) and Jiaolong Zhang (TU Wien/Tongji University) are gratefully acknowledged.

Additional interesting discussions, carried out within the VIF-project 845681 "Optimierte Bemessungsregeln für dauerhafte bewehrte Betongelenke [Optimized Rules for the Design of Permanent Reinforcement Concrete Hinges]", with Markus Vill (Vill Ziviltechniker GmbH), Michael Schweigler (TU Wien), Susanne Gmainer and Martin Peyerl (Smart Minerals GmbH), Alfred Hüngsberg (ÖBB-Infrastruktur AG), as well as Erwin Pilch and Michael Kleiser (ASFINAG Bau Management $\mathrm{GmbH}$ ) are also gratefully acknowledged. 


\section{REFERENCES}

Austrian Standards Institute (2010). ONR 23303:2010-0901 Prüfverfahren Beton (PVB) - Nationale Anwendung der Prüfnormen für Beton und seiner Ausgangsstoffe [Test protocol concrete - National application of testing standards for concrete and its raw materials]. Austrian Standards Institute. In German.

Blom, C.B.M. (2002). Design philosophy of concrete linings for tunnels in soft soils. Ph. D. thesis, Delft University of Technology.

British Standards Institution \& CEN European Committee for Standardization (2015a). EN 1992-1-1:2015-0731 Eurocode 2: Design of concrete structures - Part 1-1: General rules and rules for buildings. London: British Standards Institution and CEN European Committee for Standardization.

British Standards Institution \& CEN European Committee for Standardization (2015b). EN 1993-11:2005+A1:2014 Eurocode 3. Design of steel structures. - Part 1-1: General rules and rules for buildings. London: British Standards Institution and CEN European Committee for Standardization.

Červenka, J. \& V. Červenka (2013). Three dimensional combined fracture-plastic material model for concrete including creep and rate effect for dynamic loading. Technical report, Červenka Consulting. http://www.cervenka.cz/assets/files/papers/3D Fracture-Plastic Model v5.pdf last access: November 08, 2017.

Červenka, J. \& V.K. Papanikolaou (2008). Three dimensional combined fracture-plastic material model for concrete. International Journal of Plasticity 24(12), 2192-2220.

Červenka, V., L. Jendele, \& J. Červenka (2016). ATENA program documentation Part 1 - Theory (February 5, 2016 ed.). Červenka Consulting s.r.o.

Červenka Consulting, V. Červenka, L. Jendele, J. Červenka, et al. (2016). Build $12562 \&$ ATENA 5.1.3. Internet source.

De Waal, R.G.A. (2000). Steel fibre reinforced tunnel segments - for the application in shield driven tunnel linings. $\mathrm{Ph}$. D. thesis, Delft University of Technology.

fib (2013). fib Model Code for Concrete Structures 2010 Ernst \& Sohn, Wiley.

Freyssinet, E. (1923). Le pont de Candelier [The bridge of Candelier]. Annales des Ponts et Chaussées 1, 165f. In French.

Freyssinet, E. (1954). Naissance du béton précontraint et vues d'avenir [Birth of prestressed concrete and future outlook]. Travaux (236), 463-474. In French.

Grassl, P. \& M. Jirásek (2006, nov). Damage-plastic model for concrete failure. International Journal of Solids and Structures 43(22-23), 7166-7196.

Hlobil, M., M. Göstl, J. Burrus, C. Hellmich, \& B. Pichler (2017). Molecular-to-macro upscaling of concrete fracture: theory and experiments. Journal for the Mechanics and Physics of Solids. under revision.

Hordijk, D.A. (1991). Local approach to fatigue of concrete. $\mathrm{Ph}$. D. thesis, Delft University of Technology. ISBN 90/9004519-8.

Hordijk, D.A., F. Gijsbers, \& P. Boortunnels (1996). Laboratoriumproeven tunnelsegmenten [Laboratory testing of tunnel segments]. Technical Report Reporte Interno K100-W-026, Nederlands kenniscentrum voor ondergronds bouwen en ondergronds ruimtegebruik (COB), Delft. In Dutch.
Janßen, P. (1983). Tragverhalten von Tunnelausbauten mit Gelenkstübbings [Structural behavior of segmented tunnel linings ]. Ph.D. thesis, Technical University of Braunschweig. In German.

Jusoh, S.N., H. Mohamad, A. Marto, N.Z.M. Yunus, \& F. Kasim (2015). Segment's joint in precast tunnel lining design. Jurnal Teknologi 77(11), 91-98.

Kalliauer, J. (2016). Insight into the structural behavior of concrete hinges by means of Finite Element simulations. Master thesis, TU Wien.

Kalliauer, J., T. Schlappal, M. Vill, H. Mang, \& B. Pichler (2017). Bearing capacity of concrete hinges. Acta Mechanica. Accepted for publication.

Leonhardt, F. \& H. Reimann (1965). Betongelenke: Versuchsbericht, Vorschläge zur Bemessung und konstruktiven Ausbildung. Kritische Spannungszustände des Betons bei mehrachsiger, ruhender Kurzzeitbelastung [Concrete hinges: Test report, recomendations for structural design. Critical stress states of concrete under multiaxial static short-term loading], Volume 175. Ernst und Sohn. In German.

Leonhardt, F. (1986). Mainbrücke Gemünden - Eisenbahnbrücke aus Spannbeton mit $135 \mathrm{~m}$ Spannweite [Bridge over the river Main at Gemünden - prestressed railway bridge with a span of $135 \mathrm{~m}]$. Beton- und Stahlbetonbau 81(1), 1-8. In German.

Maidl, B., M. Herrenknecht, U. Maidl, \& G. Wehrmeyer (2012). Mechanised Shield Tunnelling. Wiley-Blackwell.

Marx, S. \& G. Schacht (2010a). Betongelenke im Brückenbau [Concrete hinges in bridge construction], Volume 18. Deutscher Beton- und Bautechnik-Verein e.v. In German.

Marx, S. \& G. Schacht (2010b). Concrete hinges - historical development and contemporary use. $3 \mathrm{rd}$ fib International Congress - 2010 3, 2822-2843.

Marx, S. \& G. Schacht (2010c). Gelenke im Massivbau [Hinges in concrete structures]. Beton- und Stahlbetonbau 105(1), 27-35. In German.

Menétrey, P. \& K.J. Willam (1995). Triaxial failure criterion for concrete and its generalization. ACI structural Journal 92(3), 311-318.

Morgenthal, G. \& P. Olney (2016). Concrete hinges and integral bridge piers. Journal of Bridge Engineering 21(1), 06015005.

Pichler, B., C. Hellmich, \& H.A. Mang (2007). A combined fracture-micromechanics model for tensile strainsoftening in brittle materials, based on propagation of interacting microcracks. International Journal for Numerical and Analytical Methods in Geomechanics 31(2), 111-132.

Ross, A. (1958). Creep of concrete under variable stress. In Journal Proceedings, Volume 54, pp. 739-758.

Sallenbach, H.H. (1967). Betongelenke beim HardturmViadukt [Concrete hinges for the Hardturm-Viadukt]. Schweizer Bauzeitung 85, 615-619. In German.

Schacht, G. \& S. Marx (2010). Unbewehrte Betongelenke 100 Jahre Erfahrung im Brückenbau [Unreinforced concrete hinges -100 years experience in bridge constructions]. Beton- und Stahlbetonbau 105(9), 599-607. In German.

Schacht, G. \& S. Marx (2015). Concrete hinges in bridge engineering. Proceedings of the Institution of Civil Engineers-Engineering History and Heritage 168(2), 65-75.

Schlappal, T., M. Schweigler, S. Gmainer, M. Peyerl, \& B. Pichler (2017). Creep and cracking of concrete hinges - insight from centric and eccentric compression experiments. Materials and Structures. Accepted for publication. 